\title{
LIFE GREENSHOES4ALL - FOOTWEAR ENVIRONMENTAL FOOTPRINT
}

\author{
MARIA JOSÉ FERREIRA, VERA V. PINTO, PATRÍCIA COSTA \\ CTCP - Portuguese Footwear Research and Technological Centre, Rua de Fundões - Devesa \\ Velha, 3700-121, São João da Madeira, Portugal, mjose.ferreira@ctcp.pt
}

\begin{abstract}
One important step towards sustainability in footwear industries is to measure and tune the environmental impact a product makes throughout its life cycle. By performing a product's life cycle assessment (LCA), the footwear value chain can produce footwear more responsibly, economically and in an eco-friendly way by addressing the three pillars of sustainability. LIFEGreenShoes4All teams are conducting LCA studies in representative footwear models ranging from fashion to safety footwear, with uppers in leather or textiles; midsoles in polyurethane foam (PU) or ethyl vinyl acetate (EVA); soles in vulcanized rubber, thermoplastic rubber (TR), EVA and others. These studies make possible to identify and quantify the most relevant life cycle stages, contributing to the most relevant impact categories (e. g, climate change, resource use), helping companies on the definition of how their footwear environmental performance may be improved. Considering the results, the higher contributors are materials and components, followed by waste from manufacturing and end-of-life. The creative design phase plays a significant role in footwear life cycle sustainability impact. The implementation of ecodesign on the product conception is crucial to reduce the Product Environmental Footprint (PEF). LIFEGreenShoes4All is being developed by 9 partners AMF, APICCAPS, ATLANTA, CEC, CTCP, EVATHINK, ICPI, INESCOP, FICE and PESTOS (https://www.greenshoes4all.eu/)
\end{abstract}

Keywords: Footwear, Product Environmental Footprint, Ecodesign

\section{BACKGROUND}

Nowadays, there is a proliferation of so called 'eco' labels or schemes, and misleading 'green' claims. Consumers find this confusing and footwear manufacturers that want to produce 'green products' find it hard to differentiate their products from these and need the right tools to do. Life Cycle Assessment (LCA) standards may be too flexible to ensure comparability of results. In this respect, Product Environmental Footprint (PEF) could play an important role.

The LIFE GreenShoes4All project is designed to support the implementation of a Product Environmental Footprint evaluation methodology, to help companies involved in the footwear business to measure the environmental performance of their products. The PEF methodology envisages to introduce several improvements compared to other existing LCA methods including, namely, clear identification of the potential environmental impact categories to be looked at, data sets and minimum data quality requirements.

LIFE GreenShoes4All project and metrics also encompasses supply chain activities from materials and products industrial production through the product use and waste management. The project will propose more tangible targets on raw materials selection, products ecodesign and manufacturing, waste polymers recycling (rubber, thermoplastic and EVA), and measures to reduce greenhouse gas emissions.

The partnership involved includes research organisations, footwear associations and manufacturers of materials, components and footwear from Belgium, Portugal, Romania, and Spain, all working to achieve these objectives. In 2020, the project opened to new EU stakeholders aiming to apply the draft PEF methodology and ecodesign approaches to footwear products and all are welcome onboard. Due to its 


\section{Life GreenShoes4All - Footwear Product Environmental Footprint}

importance this paper is dedicated to a product's life cycle evaluation using the draft PEF methodology.

\section{EXPERIMENTAL}

\section{Materials}

Five shoe models presenting aesthetics, touch, and general properties usual in casual ladies' and man's shoes were selected and the impact of feasible modifications studied. Table 1 presents generically the models, describes the main materials and components studied and details the functional unit defined to perform the PEF/LCA studies. 1-year lifetime was assumed.

Table 1. Shoe models description and functional unit

\begin{tabular}{|c|c|c|}
\hline Model & Description & Functional Unit \\
\hline Sandal & $\begin{array}{l}\text { Leather upper } \\
\text {. Leather lining } \\
\text {. TR outsole } \\
\text {. Leather upper } \\
\text {. Polyester lining } \\
\text {. TR outsole } \\
\text {. Leather upper } \\
\text {. Polyester lining } \\
\text {. PU foam outsole }\end{array}$ & $\begin{array}{l}\text { One pair of sandals, size } 37 \text {, packed. } \\
\text { Total weight: } 0,922 \mathrm{~kg} \text {. } \\
\text { Pair of shoes: } 0,628 \mathrm{~kg} \text {. } \\
\text { One pair of sandals, size } 37 \text {, packed. } \\
\text { Total weight: } 0,922 \mathrm{~kg} \text {. } \\
\text { Pair of shoes: } 0,628 \mathrm{~kg} \text {. } \\
\text { One pair of sandals, size } 37 \text {, packed. } \\
\text { Total weight: } 0,692 \mathrm{~kg} \text {. } \\
\text { Pair of shoes: } 0,397 \mathrm{~kg} \text {. }\end{array}$ \\
\hline Low boot & $\begin{array}{l}\text { Leather upper } \\
\text { Polyester lining } \\
\text { TR outsole } \\
\text {. Leather upper } \\
\text { Polyester lining } \\
\text {. PU foam }\end{array}$ & $\begin{array}{l}\text { One pair of boots, size } 37 \text {, packed. } \\
\text { Total weight: } 1,119 \mathrm{~kg} \text {. } \\
\text { Pair of shoes: } 0,825 \mathrm{~kg} \text {. } \\
\text { One pair of boots, size } 37 \text {, packed. } \\
\text { Total weight: } 0,929 \mathrm{~kg} \text {. } \\
\text { Pair of shoes: } 0,635 \mathrm{~kg} \text {. }\end{array}$ \\
\hline Medium boot & $\begin{array}{l}\text { Leather upper } \\
\text { Cotton lining } \\
\text { TR outsole } \\
\text {. Leather upper } \\
\text { Cotton lining } \\
\text { PU foam }\end{array}$ & $\begin{array}{l}\text { One pair of boots, size } 37 \text {, packed. } \\
\text { Total weight: } 1,213 \mathrm{~kg} \text {. } \\
\text { Pair of shoes: } 0,918 \mathrm{~kg} \text {. } \\
\text { One pair of boots, size } 37 \text {, packed. } \\
\text { Total weight: } 0,939 \mathrm{~kg} \text {. } \\
\text { Pair of shoes: } 0,644 \mathrm{~kg} \text {. }\end{array}$ \\
\hline High Boot & $\begin{array}{l}\text { Leather upper } \\
\text {. Polyester lining } \\
\text { TR outsole } \\
\text {. Leather upper } \\
\text {. Polyester lining } \\
\text {. PU foam } \\
\text {. Leather and synthetic } \\
\text { upper. Polyester lining } \\
\text {. PU foam }\end{array}$ & $\begin{array}{l}\text { One pair of boots, size } 37 \text {, packed. } \\
\text { Total weight: } 1,532 \mathrm{~kg} \text {. } \\
\text { Pair of shoes: } 0,993 \mathrm{~kg} \text {. } \\
\text { One pair of boots, size } 37 \text {, packed. } \\
\text { Total weight: } 1,285 \mathrm{~kg} \text {. } \\
\text { Pair of shoes: } 0,746 \mathrm{~kg} \text {. } \\
\text { One pair of boots, size } 37 \text {, packed. } \\
\text { Total weight: } 1,285 \mathrm{~kg} \text {. } \\
\text { Pair of shoes: } 0,746 \mathrm{~kg}\end{array}$ \\
\hline Men casual shoe & $\begin{array}{l}\text { Leather upper } \\
\text { EVA outsole }\end{array}$ & $\begin{array}{l}\text { One pair of shoes, size } 42, \text { packed. } \\
\text { Total weight: } 1,081 \mathrm{~kg} \text {. } \\
\text { Pair of shoes: } 0,803 \mathrm{~kg} \text {. }\end{array}$ \\
\hline
\end{tabular}




\section{PEF Method}

A PEF study is essentially a standardised LCA study aiming to ensure that environmental information is comparable and reliable and can be used confidently. During a product's life cycle assessment, environmental impacts are evaluated with a holistic view of environmental interactions that covers a range of activities, from the extraction of raw materials from the Earth, the production and distribution of energy, through the upstream and downstream processes associated with materials and products production and end-of-life (EoL).

A Footwear PEF/LCA study includes essentially five steps.

1. Define the functional unit, e.g. 'one pair of shoes including packaging' (Table 1).

2. Define the system boundary, e.g. 'cradle-to-grave system boundary'. Figure 1 shows a simplified cradle-to-grave system boundary.

3. Collect primary data, namely, the composition and weight of materials and the components employed for the manufacture of the shoes, water and energy consumption, production waste, annual total production, suppliers, and retailers' locations, and EoL.

4. Select appropriate secondary data, PEF data sets, modelling, and tools.

5. Insert data and calculate values for the impact categories defined.

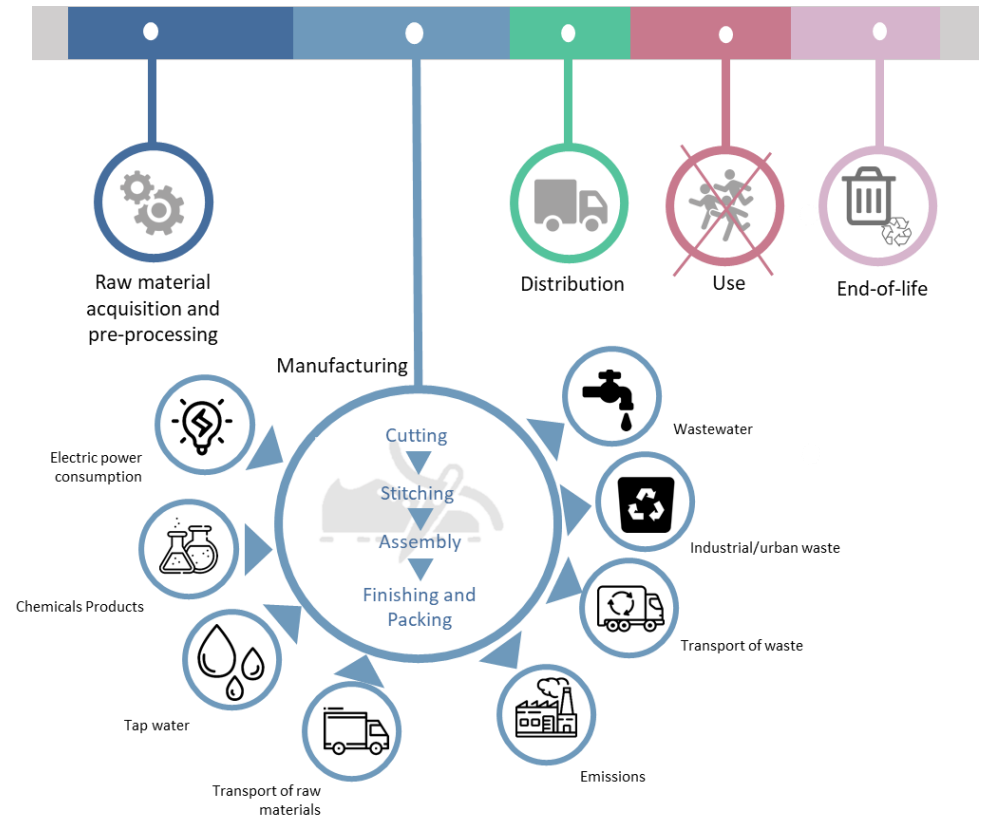

Figure 1. Life cycle stages included in the PEF/LCA study

In this study specific primary data was collected during visits to the companies and other information provided by them. Additionally, the application of alternative materials was theoretically evaluated. Since the use phase of footwear is usually insignificant its impact was not considered. Regarding secondary data, Ecoinvent database v3.3 and other data sets were used. The software used to model the data was OpenLCA 1.9. The impact categories were calculated using the EU EF method (adapted). 


\section{Life GreenShoes4All - Footwear Product Environmental Footprint}

\section{RESULTS AND DISCUSSION}

The applied footwear PEF method assesses 16 impact categories (Table 2), covering, namely, climate change, acid rain, human and ecotoxicity, and particulate matter as well as impacts due to the use of water, land, and resources.

Table 2. PEF Impact Categories, including indicators and units.

\begin{tabular}{|c|c|}
\hline Impact Categories & Indicator [Unit] \\
\hline Climate change & Global Warming Potential $\left[\mathrm{kg} \mathrm{CO}_{2} \mathrm{eq}\right]$ \\
\hline Ozone depletion & Ozone Depletion Potential [kg CFC-11eq] \\
\hline Human toxicity, cancer effects & Comparative Toxic Unit for humans [CTUh] \\
\hline Human toxicity, non-cancer effects & Comparative Toxic Unit for humans [CTUh] \\
\hline $\begin{array}{l}\text { Particulate matter, respiratory } \\
\text { inorganics }\end{array}$ & $\begin{array}{l}\text { Human health effects associated with exposure to } \\
\text { PM2.5 [Disease incidences] }\end{array}$ \\
\hline Ionizing radiation, human health & Human exposure efficiency relative to $\mathrm{U}[\mathrm{kBq} \mathrm{U}]$ \\
\hline $\begin{array}{l}\text { Photochemical ozone formation, } \\
\text { human health }\end{array}$ & $\begin{array}{l}\text { Tropospheric ozone concentration increase } \\
\text { [kg NMVOC eq] }\end{array}$ \\
\hline Acidification & Accumulated Exceedance (AE) $[\mathrm{mol} \mathrm{H}+$ eq] \\
\hline Eutrophication, terrestrial & Accumulated Exceedance (AE) [mol H+ eq] \\
\hline Eutrophication, aquatic freshwater & Fraction of nutrients to freshwater $(\mathrm{P})[\mathrm{kg} \mathrm{P}$ eq] \\
\hline Eutrophication, aquatic marine & Fraction of nutrients to marine $(\mathrm{N})[\mathrm{kg} \mathrm{N}$ eq] \\
\hline Ecotoxicity freshwater & Comparative Toxic Unit for ecosystems [CTUe] \\
\hline Land use & Soil quality index [Dimensionless*] \\
\hline Water use & User deprivation potential [kg world eq. deprived] \\
\hline Resource use, minerals and metals & Abiotic resource depletion $[\mathrm{kg} \mathrm{Sb} \mathrm{eq}]$ \\
\hline Resource use, fossils/energy carriers & Abiotic resource depletion - fossil fuels [MJ] \\
\hline
\end{tabular}

Figure 2 presents the most relevant impact categories determined based on the normalised and weighted results for a cumulative contribution of $84 \%$ of the total. The other 9 impact categories totalize $16 \%$ of the total.

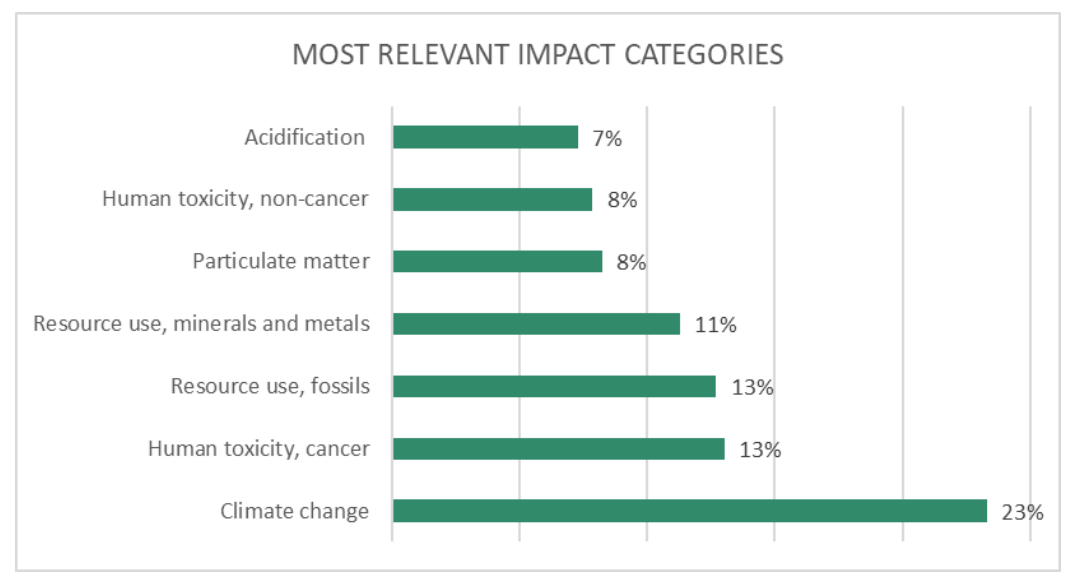

Figure 2. Most relevant impact categories calculated based on sandal 
Among these, as "Climate Change" is the most relevant impact category, and usually the more well-known, was chosen to present and discuss the environmental impact of the shoe models. Table 3 presents the results of the Climate Change impact category, Global Warming Potential indicator (GWP100), in $\mathrm{kg} \mathrm{CO}_{2}$ eq, calculated for each pair of footwear. Analysing the values of $\mathrm{kg} \mathrm{CO}_{2}$ eq obtained for the ladies' shoes, in general, an increase of the amount of materials (mass) used, results in an increase of footwear EF. Additionally, the compositions of the materials and components are relevant for the EF of footwear products. These conclusions are corroborated by the $\mathrm{kg}$ $\mathrm{CO}_{2}$ eq obtained for man's shoes, because despite the higher size, the use of specific materials results in an EF similar to some ladies' footwear.

Table 3. Impact on climate change as GWP100

\begin{tabular}{lc}
\hline \multicolumn{1}{c}{ Model } & $\mathrm{Kg} \mathrm{CO} 2 \mathrm{eq}$ \\
\hline Sandal & $6-9$ \\
Low boot & $13-15$ \\
Medium boot & $13-16$ \\
High boot & $14-19$ \\
Men casual shoe & $13-15$ \\
\hline
\end{tabular}

Figure 3 shows the contribution of each life cycle stage to the Climate Change impact category, for each shoe model type. The results indicate that materials selection and pre-processing (including, raw materials, components, adhesives, and packaging) is the most relevant life cycle stage, representing around (75 to 90) \% of the total GWP100 in $\mathrm{kg} \mathrm{CO}_{2}$ eq. The heavier components, upper and outsole, are the main EF contributors, representing on average about (70 to 90$) \%$, depending on their mass and composition. Manufacturing (including namely electricity and production waste) and EoL represent, respectively, around (4 to 18) \% and (5 to 9) $\% \mathrm{~kg} \mathrm{CO}_{2}$ eq of the total GWP100. These range of results are related with the production processes and type of models. Distribution account for less than $2 \%$ of the total GWP100 in $\mathrm{kg} \mathrm{CO}_{2}$ eq.

Based on these results is clear that reducing the mass of materials, selecting lower environmental footprint (EF) materials, and reducing the waste generated during the manufacturing of footwear will have a great effect of the reduction of footwear EF. To this end, as most of the environmental impact is decided during the design and development phase of footwear products, the implementation of ecodesign approaches will bring several benefits to footwear business companies. To reduce its PEF, a company's plan could include the following actions:

1. Design its footwear to reduce the number of different materials used.

2. Preferably select light biobased, recycled, or recyclable materials and components from local suppliers.

3. Apply efficient digitalised production processes with low energy consumption and reduced emissions and wastes.

4. Make footwear lighter and durable, easier to repair, and/or recycle.

To extend the use stage of the product, minimise the consumption of resources and the impact at EoL is important to consider designing for disassembly, recycling, reuse, or recovery; biodegradability or compostability, among other approaches. 


\section{Life GreenShoes4All - Footwear Product Environmental Footprint}

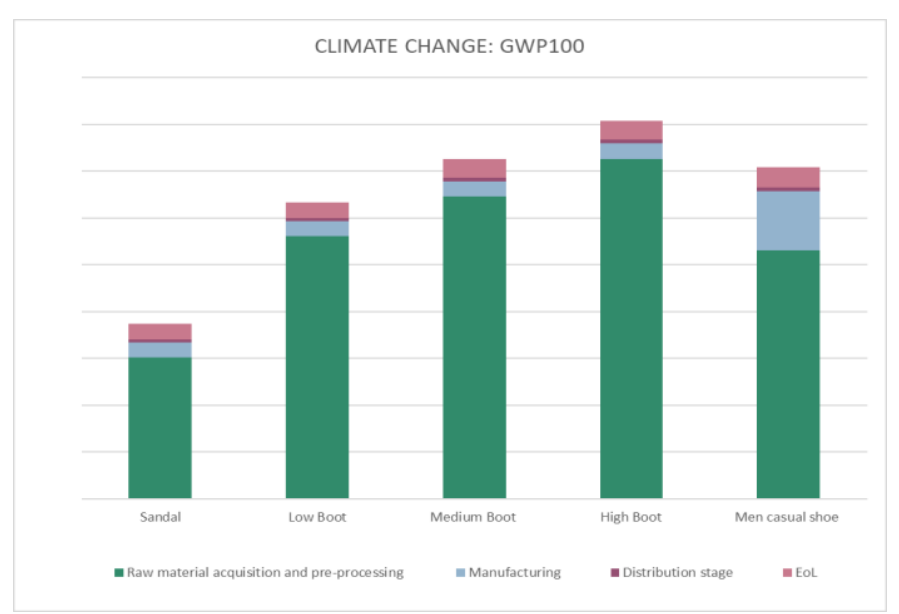

Figure 3. Contribution of each life cycle stage to the climate change impact category, using the GWP100 indicator $\left(\mathrm{Kg} \mathrm{CO}_{2} \mathrm{eq}\right)$

\section{CONCLUSIONS}

This study involves the evaluation and comparison of environmental footprint of five footwear models based on PEF method. The results indicate that for the "Climate Change" impact category, raw material acquisition and pre-processing is the most relevant life cycle stage. The reduction of footwear environmental footprint can be achieved by implementing several measures throughout the entire life cycle, namely, careful selection of materials and components (selection of lower impact raw materials), reduction of materials amount (mass), reduction of waste generation by implementing more efficient production processes (e.g., more efficient cutting process), buy local materials and use more efficient means of transport, among others. Companies will benefit from the implementation of ecodesign in the development of footwear products, since it is at this stage that the product concept, raw materials, as well as production process are defined. Additionally, adopting circular business models, aiming for the efficient use of natural resources powered by renewable energy, will add true value and environmental differentiation to footwear. Using PEF/LCA, these and other actions may be evaluated and tuned, enabling sustainable choices to be made and promoting the creation, production and use of 'truly green shoes' in a circular economy.

\section{Acknowledgements}

CTCP, the Portuguese Footwear Technology and Research Centre, thanks the support of the European project LIFE GreenShoel4All (LIFE17 ENV/PT/000337).

\section{REFERENCES}

Zampori, L. and Pant, R. (2019), "Suggestions for updating the Product Environmental Footprint (PEF) method", EUR 19682 EN, Publications Office of the European Union, Luxembourg, ISBN 978-92-7600654-1, https://doi.org/10.2760/424613, JRC115959.

*** (2015), thinkstep on Behalf of Sustainable Apparel Coalition, "First Draft Product Environmental Footprint Category Rules (PEFCR)", Rev. 0.1.

*** (2017), PEFCR Guidance document, "Guidance for the development of Product Environmental Footprint Category Rules (PEFCR)”, version 6.3, December 2017.

https://doi.org/10.24264/icams-2020.IV.6 